\title{
UM ESTUDO SÔBRE EDUCAÇÃO EM SAŨDE NAS ESCOLAS DAS FILIPINAS
}

Ruth Sandoval MARCONDES (1)

Marcondes, R. S. - Um estudo sôbre educação em saúde nas escolas das Filipinas. Rev. Saúde públ., S. Paulo, 5:103-9, 1971.

RESUMo -- Descrevem-se alguns aspectos do programa de educação em saúde nas escolas das Filipinas. O programa abrange quatro dimensões: ambiente físico e emocional da escola, serviços de saúde, ensino da saúde e relações lar-escola-comunidade. Treinamento de pessoal para educação em saúde na escola é especialmente focalizado.

UNITERMos - Educação sanitária*; Saúde Escolar*.

\section{INTRODUCAO}

A República das Filipinas é constituída por 7.000 ilhas, divididas em 3 regiōes principais: Luzon, Visayas e Mindanau. Tem 37 milhões de habitantes e 87 línguas diferentes, das quais 14 sáo usadas no $10^{\circ} \mathrm{e} 20^{\circ}$ anos primários. Inglês é a língua de instrução a partir do $3 .^{\circ}$ ano primário, nas escolas públicas, e a partir do jardim da infância nas escolas particulares.

\section{2. educacao em SaÚde nas escolas}

Interêsse nacional pela saúde dos escolares nas Filipinas evidencia-se a partir de 1911 quando o Congresso aprovou uma lei exigindo inspeçâo médica das crianças escolares a ser realizada pelo Departamento, de Saúde.

Em 1913, instrução sôbre higiene, fisiologia e saneamento foi introduzida no
VII Grau das escolas públicas e em 1926 o Govêrno aprovou o estabelecimento de um programa nacional de saúde nas escolas.

Em 1929 a Universidade das Filipinas começou a oferecer cursos de educação em saúde. Nos anos subseqüentes, o progresso em relação ao desenvolvimento de um programa de educação em saúde nas escolas foi sempre continuando até que, em 1961, o Govêrno firmou convênio com a OMS e UNICEF com o fim de desenvolver um projeto de treinamento em educação em saúde nas escolas. Êste projeto teve por objetivos:

a) Ajudar a República das Filipinas a estabelecer um programa coordenado de saúde nas escolas, de responsabilidade conjunta do Departamento de Saúde e do Departamento de Educação.

Recebido para publicação em 9-3-1971.

(1) Da Disciplina Educação em Saúde Pública, do Departamento de Pratica de Saúde Pública da Faculdade de Saúde Pública da USP - Av. Dr. Arnaldo, 715 - São Paulo, SP Brasil. 
MARCONDES, R. S. - Um estudo sôbre educacão em saúde nas escolas das Filipinas. Rev. Saúde públ., S. Paulo, 5:103-9, 1971.

b) Melhorar o programa nacional de saúde nas escolas, através do treinamento de pessoal.

c) Desenvolver o currículo de educação em saúde sob a forma de guias de instrução para professôres primários, secundários e de colégio, e

d) Avaliar o programa de educação em saúde nas escolas.

\section{NOMERO DE ESCOLAS, ALUNOS, PROFESSORES E PESSOAL DE SAODE}

O número de escolas, de alunos e de professôres na República das Filipinas é apresentado na Tabela 1 .

Quanto ao pessoal de saúde, as escolas das Filipinas contam com 1.912 profissionais e auxiliares, distribuidos conforme Tabela 2.

TABELA 1

Número de escolas, alunos e professôres - Filipinas, 1968

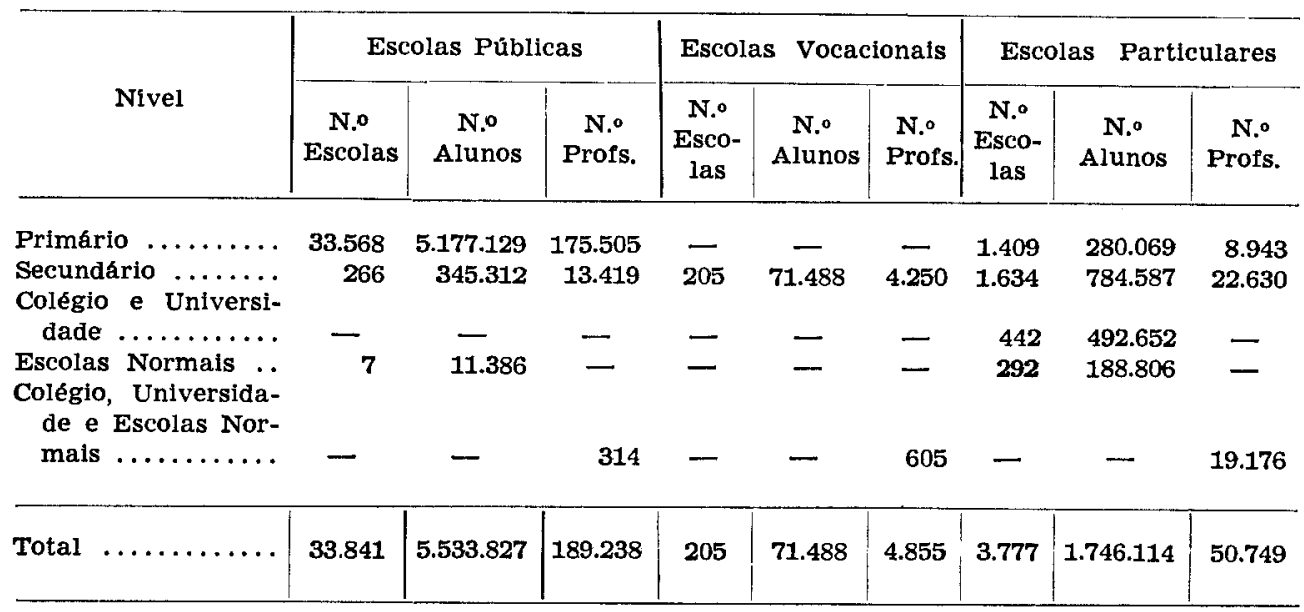

FONTE: Departamento de Educação, República das Filipinas

TABELA 2

Pessoal de saúde escolar — Filipinas, 1968

\begin{tabular}{|c|c|c|c|}
\hline Pessoal & $\begin{array}{l}\text { Escolas } \\
\text { Públicas }\end{array}$ & $\begin{array}{c}\text { Escolas } \\
\text { Vocacionais }\end{array}$ & $\begin{array}{c}\text { Escolas } \\
\text { Particulares }\end{array}$ \\
\hline 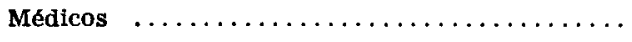 & 97 & 25 & - \\
\hline 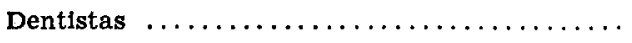 & 475 & 48 & - \\
\hline Auxiliares de Dentistas $\ldots \ldots \ldots \ldots \ldots \ldots$ & 439 & 1 & - \\
\hline Enfermeiras $\ldots \ldots \ldots \ldots \ldots \ldots \ldots \ldots \ldots \ldots \ldots \ldots \ldots$ & 610 & 158 & - \\
\hline Supervisores de Educação Sanitária ...... & 64 & 1 & 1 \\
\hline Coordenadores de Educação Sanitária .... & 一 & 1 & 1 \\
\hline Total $\ldots \ldots \ldots \ldots \ldots \ldots \ldots \ldots \ldots \ldots \ldots \ldots \ldots \ldots$ & 1.676 & 234 & 2 \\
\hline
\end{tabular}


MARCONDES, R. S. - Um estudo sôbre educação em saúde nas escolas das Filipinas. Rev. Saúde públ., S. Paulo, 5:103-9, 1971.

\section{O PROGRAMA DE EDUCACAO EM SAODE NAS ESCOLAS}

A responsabilidade pela saúde da criança cabe principalmente aos pais. Entretanto, a saúde da criança escolar nas Filipinas é legalmente atribuída a duas entidades governamentais: ao Departamento de Saúde e ao Departamento de Educação. O sistema educacional, incluindo o programa de saúde escolar, é administrado pelo Departamento de Educação.

A responsabilidade pela supervisão e contrôle das escolas cabe a três "bureaux" dentro do Departamento de Educação: ao Bureau das Escolas Públicas, das Escolas Particulares e de Educação Vocacional.

A educação em saúde nas escolas visa ajudar os alunos a "alcançar física, mental, social e moralmente seu potencial máximo hereditário". Sem saúde êste "potencial máximo" é inatingível A escola então ajuda a suplementar os esforços do lar e da comunidade na assistência às crianças e jovens para obter e manter a saúde. A professôra e a diretora tornam-se membros da "equipe de saúde" focalizando as necessidades de saúde e a prevenção de doenças, enquanto o pessoal de saúde focaliza problemas de saúde, consciente do papel dos professôres.

Nas Filipinas, o programa de saúde nas escolas abrange principalmente:

- ensino de saúde;

- serviços de saúde;

- ambiente escolar;

- cooperação escola-comunidade, tendo em vista a saúde.

\subsection{Ensino de Saúde}

Por ensino de saúde não se considera apenas a aquisição de conhecimentos sôbre saúde ou a memorização de "regras" de saúde. Antes, é a transferência daqueles conhecimentos para comportamento desejável conducente à saúde. $O$ ensino de saúde nas Filipinas é baseado nos interêsses e necessidades de saúde dos escolares, em suas atividades e experiências diárias, nos problemas e recursos de saúde da comunidade.

Atendendo às exigências do Govêrno, o ensino de saúde é desenvolvido de acôrdo com o seguinte esquema:

\begin{tabular}{lll}
\hline Nivel & Tempo & \multicolumn{1}{c}{ Matéria } \\
\hline Primário & 40 minutos por dia & $\begin{array}{l}\text { Saúde e Ciência (incluindo higiene } \\
\text { pessoal, saúde da comunidade, ciên- } \\
\text { cia elementar, conservação e segu- } \\
\text { rança) }\end{array}$ \\
\hline Secundário & 40 minutos por dia & $\begin{array}{l}\text { Saúde, Educação Física e Serviço } \\
\text { Militar. }\end{array}$ \\
\hline (2 últimos anos $)$ & 20 minutos por dia & $\begin{array}{l}\text { Saúde, Educação Física e Serviço } \\
\text { Militar. }\end{array}$ \\
\hline
\end{tabular}


MARCONDES, R. S. - Um estudo sôbre educação em saúde nas escolas das Fillipinas. Rev. Saúde puibl., S. Paulo, s:103-9, 1971.

Entretanto, além do horário oficial das "aulas de saúde", todos os momentos e oportunidades são aproveitados para integrar saúde ao programa escolar.

Doze "guias para ensino de saúde" foram produzidos nas Filipinas para serem usados em todos os niveis. Lamentàvelmente, por falta de fundos, a impressão dêsses guias tem sido insuficiente para atender todos os professôres do país.

\subsection{Serviços de Saúde}

Ao Departamento de Educação cabe supervisionar os serviços médicos escolares. As escolas públicas e vocacionais contam com médicos que trabalham nas próprias escolas. Nas escolas particulares, os serviços de saúde são providos pelo Departamento de Saúde ou por médicos, dentistas e enfermeiras contratados pelas escolas. Nas escolas públicas da zona rural êstes serviços são providos pelo Departamento de Saúde.

O Serviço Médico que dá assistência às Escolas Públicas foi criado em 1946 com o objetivo de "promover a saúde dos escolares, proteger sua saúde e corrigir os defeitos nêles encontrados", com ênfase na educação sanitária como um meio para conseguir aquêles fins. Desde sua criação, até 1960 , era mantido pela contribuiçăo voluntária de 50 centavos filipinos (em 1970, 6 pêsos e 20 centavos correspondiam a 1 dólar) dos alunos das escolas públicas.

Em 1961, q Govêrno assumiu a manutenção dos serviços, o que contribuiu para aumentar consideràvelmente o número de médicos escolares. Entretanto, atualmente com cêrca de 100 médicos, o Serviço ainda não conta com pessoal suficiente para atender tôda a população escolar. Ültimamente os médicos têm se envolvido mais com assuntos relacionados ao currículo, o que lhes permite mais oportunidades para transmitir seus conhecimentos técnicos sôbre saúde a professôres, diretores e alunos.

\subsection{Ambiente Escolar}

O ambiente escolar que pode afetar a saúde dos alunos e do pessoal é considerado sob 3 aspectos:

\section{a) Ambiente fisico}

- Iluminação e acústica

- Ventilação

- Abastecimento de água e disposição de excreta

- Facilidades para alimentação

\section{b) Clima emocional}

- Relações professor-aluno

- Relaçōes aluno-aluno

- Relações professor-pessoal administrativo

- Relações professor-pais

\section{c) Rotina}

- Horários (tempo e carga horária por matéria)

- Equilíbrio entre repouso e atividade.

Uma das grandes necessidades ainda nas Escolas das Filipinas é a provisão de abastecimentos de água e instalações sanitárias adequadas nas escolas públicas primárias e secundárias. Este problema torna-se mais intenso com a taxa alta de aumento da população e o número de residências com suprimento de água $e$ instalações sanitárias inadequados. Outro problema é o excessivo número de alunos por escola e, conseqüentemente, por classe.

\subsection{Cooperação Escola-Comunidade}

Uma das dimensões introduzidas nos últimos anos no programa de saúde escolar foi a cooperação da escola com a comunidade tendo em vista a saúde. Este é o esfôrço da escola para trabalhar com os pais e as agências da comunidade (pú- 
MARCONDES, R. S. - Um estudo sôbre educacão em saúde nas escolas das Filipinas. Rev. Saúde puibl., S. Paulo, 5:103-9, 1971.

blicas e particulares) visando a melhoria da saúde dos alunos. Esta cooperação foi implementada pela formação de Conselhos de Saúde Escolar, que identificam problemas e necessidades de saúde da escola e da comunidade, determinam prioridades e formulam programas de ação.

\section{TREINAMENTO DE PESSOAL}

O desenvolvimento do projeto de saúde escolar nas Filipinas foi possível graças ao treinamento de pessoal do Departamento de Saúde e do Departamento de Educação, em educação sanitária escolar. Programas de treinamento em três níveis foram utilizados:

a) Treinamento pré-serviço nas escolas normais, focalizando as futuras professôras.

b) Treinamento-em-serviço - para pessoal já admitido.

c) Treinamento profissional a nível de graduação e pós-graduação.

Durante os 7 anos em que vigorou 0 Convênio com a UNICEF e OMS (19611968) foram treinadas cêrca de 3.500 pessoas em educação sanitária escolar.

Vários métodos de treinamento foram utilizados e podem ser agrupados nas seguintes categorias:

a) Cursos de verão (de nível universitário)

b) Seminários

c) Cursos noturnos

d) Bôlsas de viagens e bôlsas de estudos para cursos longos, especialmente para a obtenção do grau de Mestre.

\section{CENTROS DE DEMONSTRACAO}

A título de demonstração de programas foram organizados centros de experimentação em escolas e na Universidade.
O Grupo Escolar Santo Niño, em Rizal, e o Ginásio Eulogio Rodrigues, em Quézon City, foram selecionados como escolas piloto para desenvolver a educação em saúde, em cooperação com a Escola Normal das Filipinas e a Universidade das Filipinas, respectivamente. Estas escolas serviram como laboratórios para as futuras professôras e como áreas de demonstração para o treinamento-em-serviço do pessoal do Departamento de Educação. Além disso, serviram como modelos para as 7 escolas normais regionais na seleção de outras escolas que servissem de centro de demonstração para seus alunos.

Além do treinamento de docentes dos colégios e universidades e do pessoal do Departamento de Educação, cuìdou-se da melhoria do preparo acadêmico em educação sanitária escolar dos alunos das Escolas Normais.

Para tanto, foi criado pelo Govêrno o Centro de Educação Sanitária Escola-Comunidade no "Philippine Normal College", que serviu - como ainda serve de centro de demonstração em educação sanitária para professôres primários e demais pessoal escolar.

Foi ainda criado na Universidade das Filipinas o Centro de Educação Sanitária e Laboratório de Produção, com o fim de preparar o programa de treinamento do pessoal dos Departamentos de Educação e Saúde, em educação sanitária escolar. O Govêrno financiou o prédio e algum equipamento e a UNICEF contribuiu com o equipamento médico, dental e audiovisual, papel, livros de educação sanitária, filmes.

A criação do Centro de Educação Sanitária na Universidade das Filipinas estimulou o desenvolvimento do programa de educação sanitária na Úniversidade e colocou-a em posição de liderança em relação ao preparo das normalistas e ao treinamento-em-serviço dos professôres e pessoal das escolas em educação sanitária escolar. 
MARCONDES, R. S. - Um estudo sôbre educacăo em saúde nas escolas das Filipinas. Rev. Saúde pribl., S. Paulo, 5:103-9, 1971.

7. PROGRAMAS DE EDUCAÇAO EM SAOUdE ESCOLAR NAS ESCOLAS DE FORMACAO DE PROFESSORES

A educação em saúde escolar, como parte do programa de formação de professôres, foi primeiro desenvolvida no "Philippine Normal College" e na Faculdade de Educação e Instituto de Higiene, ambos da Universidade das Filipinas. Em seguida as Escolas Normais oficiais regionais estabeleceram cursos para preparação em educação sanitária escolar, assim como o "National Teachers College", particular. No início do programa o Instituto de Higiene oferecia um Certificado de Saúde Pública (CPH) e o "Philippine Normal College" e a Faculdade de Educação davam o Certificado em Educação Sanitária Escolar (CSHE). Mais tarde a ênfase foi colocada na obtenção dos graus de Mestre (MA, MAT, MED, MPH), com especialização em educação sanitária escolar.

\section{DESENVOLVIMENTO DO CURRICULO DE EDUCAÇAO SANITARIA}

O desenvolvimento do currículo para ensino sôbre saúde foi um dos objetivos do Projeto. Preliminarmente, foi feito um levantamento dos interêsses e necessidades de saúde dos escolares em várias partes do país. Além disso, foi feito um estudo sôbre crescimento e desenvolvimento das crianças filipinas que resultou em gráficos apresentando as "características físicas, mentais, sociais, emocionais e espirituais" das crianças de 5 a 12 anos e dos adolescentes de 13 a 19 anos de idade.

Com base no levantamento e nos gráficos foi elaborado o conteúdo de saúde para cada série escolar e então desenvolvidos os guias de educação sanitária para as escolas primárias e secundárias. Desta tarefa participaram professôres, diretores, supervisores, especialistas em saúde, técnicos em currículo, que formaram 3 grupos de trabalho.

Doze guias de instrução de saúde foram preparados: 6 para o nivel primá- rio, 4 para o nível secundário e 2 para o colégio.

Os guias foram mimeografados e enviados a escolas primárias, secundárias e colégios selecionados para uso experimental e avaliação pelos professôres. Só depois de revisados foram reproduzidos $e$ distribuídos às escolas em geral.

\section{CONSIDERAÇOES FINAIS}

Desde que se estabeleceu o Convênio Govêrno-OMS-UNICEF muito progresso se fêz no sentido de reforçar ou melhorar o programa de saúde nas escolas das Filipinas a nível nacional e através de todo o país. Eventualmente os efeitos dêste programa alcançarão cada lar onde haja escolares.

O programa tornou o professor e o diretor membros da "equipe de saúde". $E$ à medida que os administradores escolares e professôres vão assumindo sua responsabilidade para promover a saúde dos escolares, conseguem a cooperação do pessoal de saúde do Departamento de Educação e do Departamento de Saúde, dos pais e das agências de saúde da comunidade, o nível de saúde dos escolares, assim como de outros membros da comunidade, pode ser melhorado, como foi demonstrado nas áreas das escolas piloto.

Entretanto, muito ainda há para se fazer, o que se evidencia pela Tabela 3 .

$$
\text { TABEL } \mathbf{3}
$$

Principais doenças ou defeitos dos escolares nas Filipinas

\begin{tabular}{c|l|c}
\hline Ordem & $\begin{array}{c}\text { Doencas ou } \\
\text { defeitos }\end{array}$ & $\%$ \\
\hline $\mathbf{1}$ & Verminoses & $\mathbf{9 3 , 2 2}$ \\
$\mathbf{2}$ & Desnutrição & $\mathbf{9 0 , 1 8}$ \\
$\mathbf{3}$ & Cárie dental & $\mathbf{5 8 , 4 6}$ \\
$\mathbf{4}$ & Doencas da pele & $\mathbf{2 4 , 2 0}$ \\
$\mathbf{5}$ & Amigdalites & $\mathbf{1 3 , 3 4}$ \\
$\mathbf{6}$ & Rinites & $\mathbf{1 1 , 2 3}$ \\
$\mathbf{7}$ & Pediculose & $\mathbf{1 0 , 8 2}$ \\
\hline
\end{tabular}

FONTE: Relatório Anual do Ministério da Educação - Filipinas, 1967. 
MARCONDES, R. S. - Um estudo sôbre educação em saúde nas escolas das Fílipinas. Rev. Saúde públ., S. Paulo, 5:103-9, 1971.

No momento está, em operação um plano quinquenal do Govêrno (1969-1974) para a melhoria do saneamento das escolas públicas, com a provisão de água potável, instalações sanitárias e iluminação.

\section{CONCLUSOES}

Em conclusão, podemos dizer que dois aspectos do programa das Filipinas merecem menção especial:

a) 0 curso de preparação de professôres de saúde para nível secundário, na Universidade das Filipinas e no "National Teachers College".

b) 0 curso de preparação de professôres primários na área da saúde no "Philippine Normal College".
Este estudo reforçou nossa convicção de que a Universidade de São Paulo deverá orientar-se no sentido de abrir, na Faculdade de Educação, um curso de Educação e Saúde no mesmo nível, por exem. plo, do Curso de Pedagogia atual.

MARCONDES, R. S. - [Health education in the Schools of the Philippines]. Rev. Saúde puibl., S. Paulo, 5:103-9, 1971.

SUMMARY - Some aspects of the school health education program in the Republic of the Philippines are described. The program is four-dimentional: physical and emotional environment, health services, health teaching and school-home-community relationships. Personnel training for school health education is particularly focused.

UNITERMS - Health Education*; School Health *. 